Research Article

\title{
Equivalent Resilient Modulus Inversion and Calculation of Different Asphalt Pavement Structures
}

\author{
Mingming Cao $\mathbb{D}^{1},{ }^{1}$ Wanqing Huang, ${ }^{1}$ Yiwen Zou, ${ }^{2}$ and Zhiyong $\mathrm{Wu}^{1}$ \\ ${ }^{1}$ Sichuan Communication Surveying and Design Institute Co., Ltd., Chengdu 61004l, China \\ ${ }^{2}$ School of Civil Engineering, Southwest Jiaotong University, Chengdu 61003l, China \\ Correspondence should be addressed to Mingming Cao; 707360021@qq.com
}

Received 9 October 2021; Accepted 9 November 2021; Published 22 November 2021

Academic Editor: Lingkun Chen

Copyright ( $(2021$ Mingming Cao et al. This is an open access article distributed under the Creative Commons Attribution License, which permits unrestricted use, distribution, and reproduction in any medium, provided the original work is properly cited.

Based on the modulus inversion theory and the equivalent principle of deflection basin, by analyzing the deflection basin data of each structure layer measured by the FWD, the obtained equivalent resilient moduli of different structural layers in three different structures (a semirigid type Asphalt pavement and two inverted asphalt pavements) were compared. At the same time, the calculated equivalent resilient modulus of the top surface of the structural layer based on the inversion method was used to modify the existing theory formula. The results show that, with the inversion method and the theoretical calculation method, the calculated equivalent resilient modulus of the top surface of the cushion layer has a small error, but the theoretical calculation method overestimates the equivalent resilient modulus of the top surface of the cement stabilized crushed stone layer and the top surface of the graded crushed stone transition layer, especially for the inverted asphalt pavement; by contrast, the corresponding result of the inversion method is closer to the value in actual engineering. While determining the equivalent resilient modulus of the cushion layer, the influence of the thickness of the cement stabilized crushed stone layer needs to be considered, and the inverted asphalt pavement structure should adopt a thicker asphalt layer to reduce the modulus deviation; at the same time, the more the structural layers and the larger the difference in the interlayer modulus ratio, the larger the deviation of equivalent resilient modulus of the top surface of the base layer; for the inverted asphalt pavement and semirigid asphalt pavement, the correction coefficients of the calculation formula of the equivalent resilient modulus of the top surface of cement stabilized gravel layer are $0.35 \sim 0.55$ and $0.65 \sim 0.75$, respectively. The inversion method can be used to determine the equivalent resilient modulus of each structural layer of the inverted asphalt pavement and semirigid asphalt pavement, and its results can provide a basis for the design of the structure reconstruction of asphalt pavement.

\section{Introduction}

During the road reconstruction design of pavement, it is necessary to know the equivalent resilient modulus of the existing pavement or the top surface of the foundation. In fact, the equivalent resilient modulus is characterized by the ability to resist the load of a multilayer system composed of soil foundation, graded crushed stone, and cement stabilized crushed stone; these materials have different modulus and thicknesses. Therefore, it is necessary to transform the multilayer structure system into a 2-layer or 3-layer equivalent semi-infinite homogeneous space system according to the equivalent physical principle of deflection value and flexural stress [1-3]. At present, most studies mainly focus on solving the equivalent resilient modulus of the foundation or the cement concrete. The conversion formula of the equivalent resilient modulus of the foundation was modified according to the equivalent principle of deflection and introduced the correction coefficient of the influence of the load action radius; this formula is suitable for conversion of equivalent resilient modulus of the top surface of the base layer [4-6]. A method to calculate the equivalent resilient modulus of the top surface of the cement concrete pavement base layer was proposed based on different equivalence principles such as deflection, flexural stress, and temperature [7-11]. Besides, the influence of the contact situation between layers on the calculation results was also considered, but the calculation result based on the 
bending-tension stress and temperature was poor; particularly, it is difficult to effectively monitor bending-tension stress, and the equivalent principle based on the deflection value has a wide range of applications. Jiang and Yao [12] and Tan et al. [13] proposed the approximate conversion formula of the multilayer structure under different load forms (single circle, double circle wheel load) and regressed the calculation formula of the equivalent modulus of the top surface of the double-layer structure under different interlayer contact conditions (smooth, continuous). Vakili [14] established an equivalent modulus calculation model for simple pavement structure layer (the pavement structure layer on the subgrade is regarded as a two-layer elastic layered system) and verified the accuracy of the model using the inversion method (the ratio of pavement equivalent modulus to subgrade modulus).

In the structure design of cement concrete pavement, the equivalent resilient modulus of the top surface of the structural layer needs to be solved; the existing research mainly focuses on the equivalent resilient modulus of the top surface of the cement concrete pavement or soil foundation [15-20], but the asphalt material pavement has obvious viscoelastic properties; the influence of temperature must be considered in calculation or correction; besides, due to the high complexity of structural and material properties, there are relatively few studies on the equivalent resilient modulus of asphalt pavement. Based on the design method of the overlay layer, Guo et al. [21] calculated the minimum equivalent resilience modulus of the top surface of the crushed layer under different structural combinations and did not study the calculation method of the equivalent resilience modulus. According to the theory of section bending stiffness, Tan and $\mathrm{Yu}$ [22] studied the equivalent resilient modulus of asphalt surface layer and considered the contact conditions between different layers. In addition, by comparing the inverse calculated modulus of the indoor dynamic triaxial test, rotary compaction molding, and the test road structure, $\mathrm{Xu}$ et al. [23] studied the correction coefficient of the modulus inversion value. Cao et al. [24] research showed that the structure of the inverse asphalt pavement was more complex, and the traditional modulus inversion error was larger than the inversion value of the semirigid asphalt pavement; besides, the layer-by-layer inversion method can improve the accuracy of the modulus inversion. Considering the current equivalent resilience modulus research is mainly based on the theoretical calculation and analysis of semirigid asphalt pavement, without too much field verification, in this paper, by testing the dynamic deflection of three pavement structures by layer, the equivalent resilient modulus of the top surface of the cushion layer, the top surface of the base layer, and the top surface of the transition layer was determined using the inversion method, which was also used to correct theoretical calculation formula, providing the basis for the road overlay design of the semirigid asphalt pavement and inverted asphalt pavement.

\section{The Test Pavement Structure and Equivalent Resilient Modulus Inversion Method}

2.1. The Test Pavement Structure. The test section of SuiGuang Expressway adopted two kinds of structural forms, the semirigid asphalt pavement (S1) and inverted asphalt pavement (S2 and S3), as shown in Table 1. The traffic grade of Sui-Guang Expressway is heavy traffic grade.

\subsection{Theoretical Calculation Method for Determining Equiv-} alent Resilient Modulus. While using the theoretical calculation method to calculate the equivalent resilient modulus, firstly, the structural layer is converted into an equivalent single-layer structure (Figure 1); then, the equivalent resilient modulus of the top surface of the cement stabilized crushed stone layer is calculated as follows [1]:

$$
\begin{aligned}
& E_{t}=a h_{x}^{b} E_{0}\left(\frac{E_{x}}{E_{0}}\right)^{1 / 3} \\
& a=6.22\left[1-1.51\left(\frac{E_{x}}{E_{0}}\right)^{-0.45}\right] \\
& b=1-1.44\left(\frac{E_{x}}{E_{0}}\right)^{-0.55}
\end{aligned}
$$

where $E_{t}$ represents the equivalent resilient modulus of the top surface of the cement stabilized crushed stone layer $(\mathrm{MPa}), E_{x}$ represents the modulus of cement stabilized crushed stone layer $(\mathrm{MPa}), H_{x}$ represents the thickness of cement stabilized crushed stone layer $(\mathrm{m}), E_{0}$ represents the resilient modulus of the top surface of the graded crushed stone cushion layer $(\mathrm{MPa})$, and a and $b$ are regression coefficients relating to $E_{x} / E_{0}$.

In addition, the equivalent modulus of the top surface of the graded crushed stone cushion layer is calculated using formulas (2) and (3) in the "Standard for Design of Highway Cement Concrete JTG D40-2011.”

$$
\begin{aligned}
E_{2 t} & =\left(\frac{E_{3}}{E_{4}}\right)^{\alpha} E_{4}, \\
\alpha & =0.86+0.26 \operatorname{Inh}_{3},
\end{aligned}
$$

where $E_{2 t}$ represents the equivalent modulus of the top surface of the graded crushed stone cushion layer $(\mathrm{MPa}), E_{3}$ and $h_{3}$ represent the modulus (MPa) and thickness $(\mathrm{m})$ of the graded crushed stone cushion layer, respectively, $E_{4}$ represents the modulus of the soil foundation (MPa), and $a$ is the regression coefficient. Besides, while calculating the equivalent modulus of the top surface of the graded gravel transition layer using (2) and (3), the lower structure is used as the base. 
TABLE 1: The structure of the test section.

\begin{tabular}{|c|c|c|c|}
\hline Pavement structure & S1 (semirigid structure) & S2 (inverted structure 1) & S3 (inverted structure 2) \\
\hline $\begin{array}{l}\text { The asphalt mastic macadam SMA upper } \\
\text { surface layer }(\mathrm{cm})\end{array}$ & & 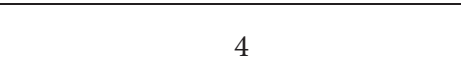 & \\
\hline $\begin{array}{l}\text { The SBS modified asphalt AC-20C middle } \\
\text { surface layer }(\mathrm{cm})\end{array}$ & & 6 & \\
\hline The lower surface laver $\quad$ The type & Asphalt AC-20C & The SBS modified asphalt AC-20C & ATB-25 \\
\hline The lower surface layer The thickness $(\mathrm{cm})$ & 8 & 8 & 12 \\
\hline $\begin{array}{l}\text { The graded crushed stone transition layer } \\
(\mathrm{cm})\end{array}$ & - & 12 & \\
\hline $\begin{array}{l}\text { The cement stabilized crushed stone base } \\
(\mathrm{cm})\end{array}$ & 28 & 20 & \\
\hline $\begin{array}{l}\text { The cement stabilized crushed stone subbase } \\
(\mathrm{cm})\end{array}$ & 28 & 24 & 20 \\
\hline The graded crushed stone cushion layer $(\mathrm{cm})$ & 15 & 15 & 15 \\
\hline The total pavement thickness $(\mathrm{cm})$ & 89 & 89 & 89 \\
\hline
\end{tabular}

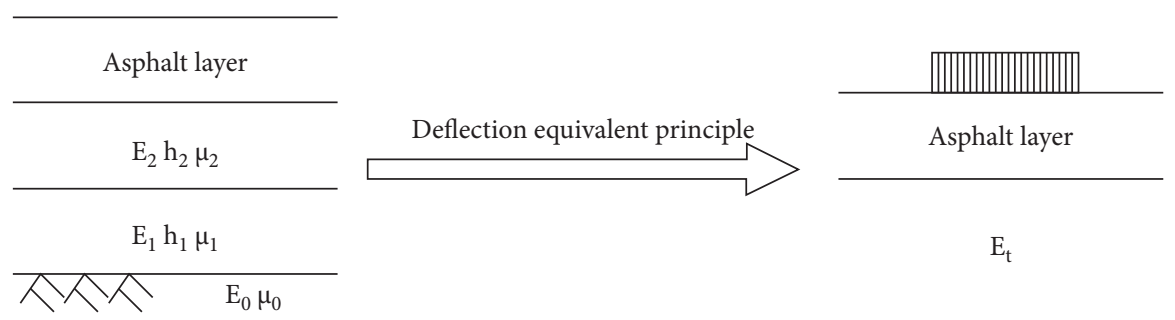

Figure 1: Conversion model of equivalent principle of deflection.

2.3. The Method of Determining the Equivalent Resilient Modulus Based on Deflection. During the calculation of the equivalent resilient modulus, the calculated theoretical equivalent modulus through multiple double-layer conversion is greater than the result of one double-layer conversion $[8,25]$, and it was believed that the deviation of the calculation results of these two conversion methods is mainly due to the difference in load distribution on the top surface of different structural layers, which means the actual load effect is smaller and the load distribution on the top surface of each structural layer is mostly in the shape of bell rather than the uniform distribution. Therefore, in order to prevent the overestimation of equivalent modulus using multiple double-layer conversions and to make it conform to the actual field value, the inversion method was proposed in this paper. Based on the theory of elastic layered system, the inversion method adopts the tested deflection of the top surface of each structural layer by FWD as the basic data and regards the modulus of each structural layer calculated with the aid of the inversion program as the structural layer modulus; moreover, the designated structural layer and lower structural layer are considered as one layer, to determine the equivalent resilient modulus of the top surface of the designated structural layer using the inversion method again. While using the inversion method to determine the equivalent resilient modulus, the variable is only the equivalent resilient modulus, which avoids the tedious process of multiple double-layer conversions, reduces the variable number, and improves inversion accuracy. The existing pavements are often unable to test the top surface deflection and sink of the top surface of each structural layer, and the modulus can be inverted based on the deflection and sink of road surface.

A more advanced iteration method was adopted, in which based on the assumed structural layer modulus, the theoretical deflection basin is calculated using the mechanical calculation method. By analyzing the difference in deflection basin between the actual measurement and the theoretical calculation, the new assumed combination of structural layer modulus is determined; then, the calculation is repeated until the mean square error between the measured and the theoretical deflection basin reached the minimum value, and the ending condition is set as the iterations number or the preassumed convergence accuracy [26].

\section{Deflection Data of Different Pavement Structures}

Following the "Field Test Regulations of Highway Subgrade and Pavement" (JTGE60-2008), the PRIMAX1500 FWD (Figure 2) was used to test the dynamic deflection basin of the top surface of the base layer, the graded crushed stone transition layer, the lower layer, the middle layer, and the upper layer. The distance between the sensor and the center of the loading plate is shown in Table 2. The FWD test of the cement stabilized crushed stone base layer is performed 30 days after its construction is completed, and the subsequent test intervals of each layer are within $48 \mathrm{~h}$. 


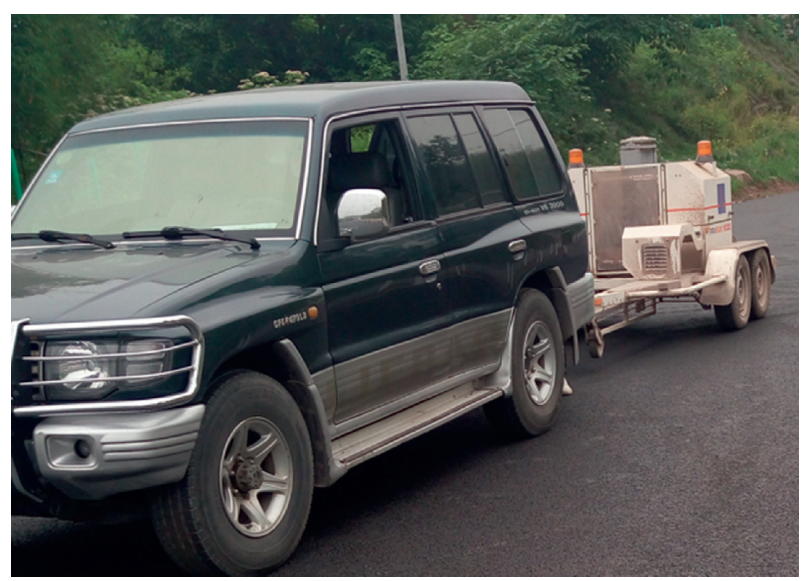

Figure 2: FWD field testing.

TABLE 2: The distance between the sensor and the center of the loading plate.

The distance between the sensor and the center of the loading plate $(\mathrm{cm})$

\begin{tabular}{lllllllllll}
\hline 0 & 20 & 30 & 40 & 50 & 60 & 90 & 120 & 150 & 180 & 210 \\
\hline
\end{tabular}

\section{Comparison of Calculated Equivalent Modulus of Different Structures}

4.1. Calculation and Comparison of Equivalent Resilient Modulus of Top Surface of Cushions with Different Structures. Based on the deflection basin data of the top surface in the FWD test, the inversion method and theoretical calculation method were used to determine the equivalent resilient modulus of the cushion top surface, as shown in Tables 3 and 4. For the three test sections, the roadbed and graded crushed stone cushions layers all adopt the same construction technology, raw materials, and construction team. The tested roadbed is uniformly compacted, and its compaction is greater than $96 \%$, with a maximum of $98.3 \%$, and an average of $97.4 \%$. The compaction of graded crushed stone cushions layer is greater than $97 \%$, with a minimum of $97.9 \%$, a maximum of $108.4 \%$, and an average of $102 \%$. In theory, the equivalent resilience modulus of the top surface of any cushion in the test section should be basically the same. However, the equivalent resilience modulus determined by the inversion method or theoretical calculation method is not the same, structure S3<structure S2 < structure S1. At the same time, the thickness values of the cement stabilized crushed stone layer of structure S1, structure S2, and structure S3 are $56 \mathrm{~cm}, 44 \mathrm{~cm}$, and $40 \mathrm{~cm}$, respectively. It can be inferred that the thickness of the cement stabilized crushed stone layer affects the inversion result of the equivalent resilient modulus. With the theoretical calculation method, the calculated equivalent modulus of the top surface of structure S1 cushion layer is 1.11 times that of structure S2 and 1.28 times that of structure S3; at the same time, with the inversion method, the determined equivalent modulus of the top surface of structure S1 cushion layer determined is 1.16 times that of structure S2 and 1.40 times that of structure S3; it can be seen that when the thickness of the cement stabilized crushed stone layer is thin, for the same decrease of the thickness of the cement stabilized crushed stone layer, the reduction in the equivalent modulus of the cushion top surface is greater than that of thick cement stabilized crushed stone layer. Besides, the decrease of the equivalent modulus of the cushion top surface determined by the inversion method is more than the result of the theoretical calculation method, suggesting it is important to accurately test the thickness of the cement stabilized gravel layer for using the inversion method to determine the equivalent modulus of the top surface of cushion layer.

The difference in the determined equivalent resilient modulus of the cushion top surface between the theoretical calculation method and the inversion method was structure S3 < structure S2 < structure S1, but the absolute values of the deviation were all within $10 \%$, so it can be concluded that the equivalent resilient moduli determined by these two methods are basically the same, and they can be used to determine the equivalent resilient modulus of the top surface of cushion layer of semirigid asphalt pavement and inverted asphalt pavement.

\subsection{Calculation and Comparison of Equivalent Resilient} Modulus of the Top Surface of Different Base Structures. Based on the FWD deflection basin data, the equivalent resilient modulus of the top surface of the base layer was determined using the inversion method and theoretical calculation method, as shown in Tables 5 and 6. It can be seen that the equivalent resilient modulus of the top surface of the base layer of structure S1 was greater than that of structures S2 and S3, and the value of structure S3 was the smallest. When FWD is subjected to the top surface of the asphalt layer, the thickness and characteristics of the asphalt layer (such as temperature) will affect the equivalent resilient modulus value of the top surface of the base layer. According to Table 6, for structure S1, based on the deflection basin data of the top surface of the lower layer tested by FWD, the equivalent resilient modulus of the base layer top surface determined by the inversion method was 1.38 and 1.37 times that based on deflection basin data of the top surface of the middle layer and the upper layer; at the same time, its value determined by the theoretical calculation method was 1.64 times and 1.59 times that based on deflection basin data of the top surface of the middle layer and the upper layer.

In addition, compared with the theoretical calculation method, the deviation value of the equivalent resilient modulus of the top surface of the cushion determined by the inversion method (Table 3 ) is significantly smaller than that of the equivalent resilient modulus of the base layer top surface (Tables 5 and 6). The equivalent resilient modulus of the top surface of the cushion is the equivalent of the modulus of the subgrade and the graded crushed stone cushion layer, their modulus ratio was less than 3 , and the thickness of the cushion layer was small. The subgrade is a half-space infinite elastic body, and the equivalent resilience modulus of the top surface of the cushion layer is 
TABLE 3: The calculation of equivalent resilient modulus of the top surface of the cushion layer when FWD is loaded on the top surface of the base layer.

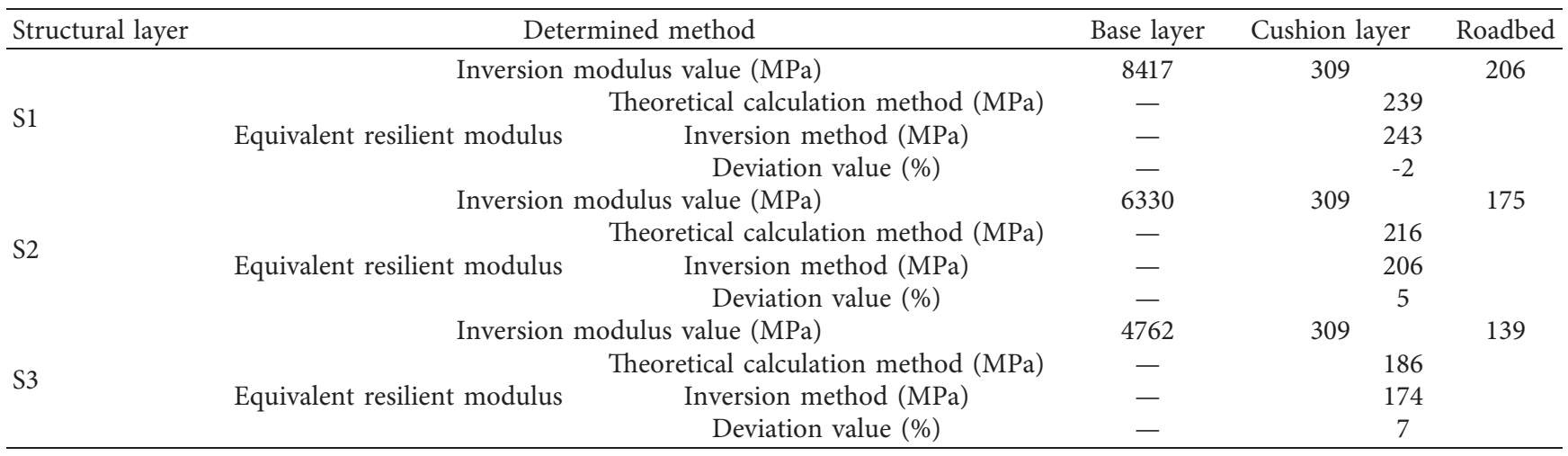

TABLE 4: Determination of equivalent resilient modulus of cushion top surface based on road surface deflection.

\begin{tabular}{|c|c|c|c|}
\hline Structural layer & Determined method & Cushion layer & Roadbed \\
\hline \multirow{4}{*}{ S1 } & Inversion modulus value (MPa) & 309 & 141 \\
\hline & Theoretical calculation method (MPa) & 188 & \\
\hline & Inversion method $(\mathrm{MPa})$ & \multicolumn{2}{|c|}{195} \\
\hline & Deviation value $(\%)$ & \multicolumn{2}{|c|}{-4} \\
\hline \multicolumn{2}{|r|}{ Inversion modulus value (MPa) } & 309 & 138 \\
\hline \multirow{4}{*}{$\mathrm{S} 2$} & Theoretical calculation method $(\mathrm{MPa})$ & \\
\hline & Equivalent resilient modulus & \multicolumn{2}{|c|}{197} \\
\hline & Deviation value $(\%)$ & \multicolumn{2}{|c|}{-6} \\
\hline & Inversion modulus value $(\mathrm{MPa})$ & 309 & 152 \\
\hline \multirow{3}{*}{ S3 } & Theoretical calculation method $(\mathrm{MPa})$ & \multicolumn{2}{|c|}{197} \\
\hline & Equivalent resilient modulus & \multicolumn{2}{|c|}{181} \\
\hline & Deviation value (\%) & \multicolumn{2}{|c|}{9} \\
\hline
\end{tabular}

mainly determined by the subgrade modulus; while determining the equivalent resilience modulus of the top surface of the base layer, the thickness of the cement stabilized crushed stone layer is large, its modulus is more than 10 times that of the subgrade or graded crushed stone, and the load is mainly borne by the roadbed and the cement stabilized crushed stone layer. Therefore, the determined equivalent resilient modulus of the top surface of the base layer is far greater than the subgrade modulus and smaller than the modulus of the cement stabilized crushed stone layer, and thicker cement-stabilized crushed stone layer or larger subgrade modulus can improve the equivalent resilience modulus of the top surface of the base layer. At the same time, while calculating the equivalent resilient modulus of the top surface of the base layer with the theoretical calculation method, the three-layer system of cement-stabilized crushed stone layer, cushion layer, and subgrade is transformed into a one-layer system, and more conversion times will increase the deviation of the calculated equivalent resilient modulus of the top surface of the base layer. Besides, the more the structural layers in the inversion or calculation of the equivalent resilient modulus, the greater the modulus ratio of the interlayer, and the greater the deviation of the equivalent modulus of elasticity determined by the inversion method compared with the theoretical calculation method.
4.3. Comparison and Calculation of Equivalent Resilient Modulus of the Top Surface of Transition Layer with Different Structure. Based on the FWD test deflection basin data of asphalt upper layer, middle surface layer, and lower layer of structure S2 and structure S3, the inversion method and theoretical calculation method were used to determine the equivalent resilient modulus of the top surface of the graded gravel transition layer, as shown in Table 7 . It can be seen that the equivalent resilient modulus obtained by the theoretical calculation method was about 1.7 2.4 times that of the inversion method. Based on the FWD test deflection basin data of the lower layer of the asphalt, compared to the result of the theoretical calculation method, the deviation of equivalent resilient modulus of structure S2 determined by the inversion method was greater than that of structure S3, and this deviation value decreased with the increase of the number of asphalt surface layers; besides, a thick asphalt layer can reduce this deviation. Therefore, while determining the equivalent resilient modulus of the top surface of the transition layer, it is better to use FWD to test the deflection basin data of the asphalt upper layer. This is because the increase of the thickness of the asphalt layer increases the weight of the superstructure so as to improve the confining pressure of the loaded part of the graded crushed stone, making the modulus of the graded crushed stone layer become higher and the internal force of the graded crushed 
TABLE 5: The calculation of the equivalent resilient modulus of the top surface of the base layer when FWD is loaded on the top surface of the transition layer.

\begin{tabular}{|c|c|c|c|c|c|c|c|c|}
\hline \multirow{3}{*}{$\begin{array}{l}\text { Structural } \\
\text { layer }\end{array}$} & \multicolumn{4}{|c|}{ S2 } & \multicolumn{4}{|c|}{ S3 } \\
\hline & \multirow[b]{2}{*}{$\begin{array}{c}\text { Inversion } \\
\text { modulus } \\
\text { value }(\mathrm{MPa})\end{array}$} & \multicolumn{3}{|c|}{ Equivalent resilient modulus } & \multirow[b]{2}{*}{$\begin{array}{c}\text { Inversion } \\
\text { modulus } \\
\text { value }(\mathrm{MPa})\end{array}$} & \multicolumn{3}{|c|}{ Equivalent resilient modulus } \\
\hline & & $\begin{array}{c}\text { Theoretical } \\
\text { calculation } \\
\text { method }(\mathrm{MPa})\end{array}$ & $\begin{array}{c}\text { Inversion } \\
\text { method } \\
(\mathrm{MPa}) \\
\end{array}$ & $\begin{array}{l}\text { Deviation } \\
\text { value (\%) }\end{array}$ & & $\begin{array}{c}\text { Theoretical } \\
\text { calculation } \\
\text { method (MPa) }\end{array}$ & $\begin{array}{c}\text { Inversion } \\
\text { method } \\
(\mathrm{MPa}) \\
\end{array}$ & $\begin{array}{l}\text { Deviation } \\
\text { value (\%) }\end{array}$ \\
\hline $\begin{array}{l}\text { Transition } \\
\text { layer }\end{array}$ & 243 & - & - & - & 243 & - & - & - \\
\hline Base layer & 6330 & & & & 4762 & & & \\
\hline $\begin{array}{l}\text { Cushion } \\
\text { layer and } \\
\text { roadbed }\end{array}$ & 134 & 1121 & 762 & 47 & 101 & 780 & 360 & 117 \\
\hline
\end{tabular}

TABLE 6: Calculation of equivalent resilient modulus of the top surface of structure S1.

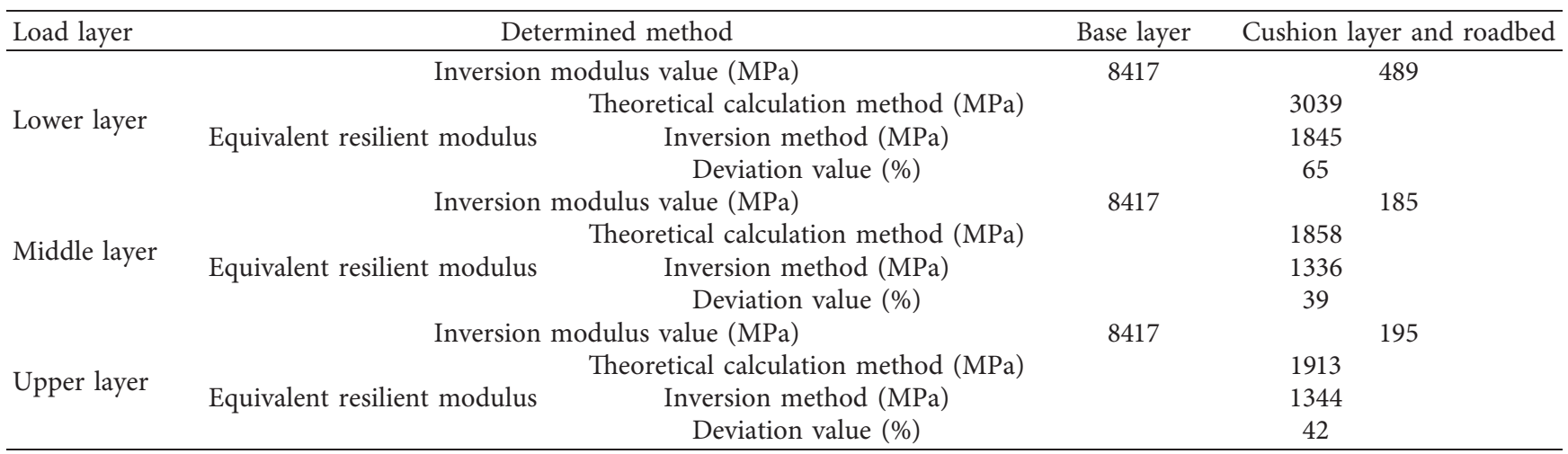

TABle 7: Calculation of the equivalent resilient modulus of the top surface of the graded gravel transition layer.

\begin{tabular}{|c|c|c|c|c|c|c|c|c|}
\hline \multirow{3}{*}{$\begin{array}{l}\text { Structural } \\
\text { layer }\end{array}$} & \multirow[b]{3}{*}{$\begin{array}{c}\text { Inversion } \\
\text { modulus } \\
\text { value }(\mathrm{MPa})\end{array}$} & \multicolumn{3}{|l|}{$\mathrm{S} 2$} & \multicolumn{4}{|c|}{ S3 } \\
\hline & & \multicolumn{3}{|c|}{ Equivalent resilient modulus } & \multicolumn{4}{|c|}{ Equivalent resilient modulus } \\
\hline & & $\begin{array}{l}\text { Theoretical } \\
\text { calculation } \\
\text { method (MPa) }\end{array}$ & $\begin{array}{l}\text { Inversion } \\
\text { method } \\
(\mathrm{MPa})\end{array}$ & $\begin{array}{l}\text { Deviation } \\
\text { value }(\%)\end{array}$ & $\begin{array}{l}\text { Inversion } \\
\text { modulus } \\
\text { value (MPa) }\end{array}$ & $\begin{array}{l}\text { Theoretical } \\
\text { calculation } \\
\text { method (MPa) }\end{array}$ & $\begin{array}{c}\text { Inversion } \\
\text { method } \\
(\mathrm{MPa})\end{array}$ & $\begin{array}{l}\text { Deviation } \\
\text { value (\%) }\end{array}$ \\
\hline \multicolumn{9}{|c|}{ FWD loading on the top surface of the lower layer } \\
\hline $\begin{array}{l}\text { Transition } \\
\text { layer }\end{array}$ & 243 & \multirow{3}{*}{837} & & & 243 & \multirow{3}{*}{546} & \multirow{3}{*}{270} & \multirow{3}{*}{102} \\
\hline $\begin{array}{l}\text { Base layer } \\
\text { Cushion }\end{array}$ & 6330 & & 351 & 138 & 4762 & & & \\
\hline $\begin{array}{l}\text { layer and } \\
\text { roadbed }\end{array}$ & 212 & & & & 102 & & & \\
\hline \multicolumn{9}{|c|}{ FWD loading on the top surface of the middle layer } \\
\hline $\begin{array}{l}\text { Transition } \\
\text { layer }\end{array}$ & 243 & \multirow{3}{*}{684} & & & 243 & \multirow{3}{*}{578} & \multirow{3}{*}{278} & \multirow{3}{*}{108} \\
\hline $\begin{array}{l}\text { Base layer } \\
\text { Cushion }\end{array}$ & 6330 & & 356 & 92 & 4762 & & & \\
\hline $\begin{array}{l}\text { layer and } \\
\text { roadbed }\end{array}$ & 127 & & & & 117 & & & \\
\hline \multicolumn{9}{|c|}{ FWD loading on the top surface of the upper layer } \\
\hline $\begin{array}{l}\text { Transition } \\
\text { layer }\end{array}$ & 243 & \multirow{3}{*}{813} & & & 243 & \multirow{3}{*}{685} & \multirow{3}{*}{358} & \multirow{3}{*}{91} \\
\hline $\begin{array}{l}\text { Base layer } \\
\text { Cushion }\end{array}$ & 6330 & & 467 & 74 & 4762 & & & \\
\hline $\begin{array}{l}\text { layer and } \\
\text { roadbed }\end{array}$ & 197 & & & & 181 & & & \\
\hline
\end{tabular}


TABle 8: Determination of the equivalent resilient modulus of the top surface of the structural layer.

\begin{tabular}{|c|c|c|c|c|}
\hline \multirow{2}{*}{ Structure } & \multirow{2}{*}{ Structural layer } & \multicolumn{3}{|c|}{ Equivalent resilient modulus (MPa) } \\
\hline & & Theoretical calculation method & Corrected theoretical calculation method & Inversion method \\
\hline Semirigid structure & Base layer & 835 & 585 & 535 \\
\hline \multirow{2}{*}{ Inverted structure } & Base layer & 483 & 217 & 211 \\
\hline & Transition layer & 532 & 239 & 233 \\
\hline
\end{tabular}

stone layer more uniform; furtherly, the effect of the error on the equivalent resilient modulus is reduced, and the accuracy of the inversion of the equivalent resilient modulus of the top surface of the transition layer is improved.

\section{Modification of the Theoretical Calculation Formula of Equivalent Resilient Modulus}

According to the analysis above, it can be known that the determination of the equivalent resilient modulus of the top surface of the cushion layer is less affected by the pavement structure, and the existing calculation method has high accuracy. Formulas (2) and (3) are recommended. For the equivalent resilient modulus of the top surface of the base layer, when $E_{d} / E_{s} \approx 47$, the deviation of the resilient modulus of structure $S 3$ determined by theoretical calculation method and the inversion method is up to $117 \%$, while the deviation of structure S2 is $47 \%$, so except the modulus ratio, factors such as the type of pavement structure and the FWD loading layer position should also be considered while deriving the calculation formula of the equivalent modulus of the base layer. Due to the different structure types and the different FWD loading position, the equivalent resilient modulus of the top surface of each structural layer determined by the calculation method and the inversion method is different. Therefore, by regressively and comparatively analyzing the equivalent resilient modulus of the top surface of each structural layer determined by the theoretical calculation and inversion, their difference is eliminated by introducing the correction coefficient $k_{1}$ to formula (1), which is $0.65 \sim 0.75$ for semirigid asphalt pavement, and $0.35 \sim 0.55$ for inverted asphalt pavement. The large difference in structural characteristics results in a significant difference in the correction coefficient of equivalent modulus theoretical calculation formula of semirigid asphalt pavement and inverted asphalt pavement. The specific value of $k_{1}$ depends on the thickness of the asphalt layer and the FWD loading position; the closer the FWD loading position to the top surface of the base layer, the closer the value to the upper limit. After the correction, the calculation of the equivalent modulus of the top surface of the base is shown in formula (2), in which the regression parameters $a$ and $b$ are calculated as before. Compared to the inversion method, the deviation of the equivalent resilient modulus of the top surface of the base layer determined by the corrected calculation method is within $20 \%$, with a maximum value of $19 \%$.

$$
E_{t}=k_{1} a h_{x}^{b} E_{0}\left(\frac{E_{x}}{E_{0}}\right)^{1 / 3}
$$

While using modified formulas (2)-(4) to calculate the equivalent resilient modulus of the top surface of the graded crushed stone transition layer, $k_{1}$ was taken as 0.35 to obtain the deviation within $20 \%$ compared with the inversion method, and the maximum deviation is $16 \%$; this calculation accuracy meets the requirements of engineering applications.

In order to verify the reliability of the calculation formula for the equivalent resilience modulus of the top surface of the structural layer based on the corrected measured deflection basin data, two kinds of asphalt pavement structures in Sichuan were selected [27], and the determined equivalent resilient modulus of the top surface of the base layer with different methods is shown in Table 8. The correction coefficient $k_{1}$ of the semirigid structure was 0.7 , and the correction coefficient $k_{1}$ of the inverted structure was 0.45. Compared with the inversion method, the deviation of using the corrected theoretical calculation method is within $10 \%$, which is much decreased. It can be seen that using the modified theoretical calculation formula to calculate the equivalent resilient modulus of the top surface of the structure layer is more in line with the actual value.

\section{Conclusions}

(1) The equivalent resilient modulus is influenced by factors such as pavement structure characteristics (thickness of adjacent layers, structure type, etc.), material characteristics, and loading layer position. The thin cement stabilized crushed stone layer or asphalt surface layer in the inverted asphalt pavement is not conducive to accurately determining the equivalent resilient modulus value of the structural layer.

(2) Generally, in terms of the deviation of the equivalent resilient modulus of the top surface of the cushion layer determined by the theoretical calculation method and the inversion method, the semirigid asphalt pavement is smaller than the inverted asphalt pavement, and the deviation using these two methods is less than $10 \%$. However, for the equivalent resilience modulus of the top surface of the base layer and the equivalent resilience modulus of the top surface of the transition layer, this deviation is larger than $40 \%$ and $70 \%$, respectively. Therefore, these two methods can be used to determine the equivalent resilience modulus of the top surface of the cushion layer, but the inversion method should be preferred while determining the equivalent resilient modulus under other working conditions. 
(3) With using the corrected calculation formula of the equivalent resilient modulus of the top surface of the cement stabilized crushed stone layer, the calculated equivalent resilient modulus of the top surface of the transition layer is close to that obtained by the inversion method, which means the distortion of equivalent resilient modulus calculated by theoretical calculation method comes from the calculation formula of equivalent modulus of the top surface of cement-stabilized crushed stone layer; based on this, the correction coefficient of structure type is introduced.

(4) The accuracy of the equivalent resilient modulus determined by the inversion method is higher than that of the theoretical calculation method and more in line with the actual value. While determining the equivalent resilient modulus of the asphalt pavement structure, the inversion method is more suitable; when the test conditions are insufficient, the modulus of the structural layer of similar engineering can be considered to be substituted into the correction formula to calculate the equivalent resilient modulus of the top surface of the structural layer.

\section{Data Availability}

The data used to support the findings of this study are available from the corresponding author upon request.

\section{Conflicts of Interest}

The authors declare that they have no conflicts of interest.

\section{Acknowledgments}

This study was supported by the Sichuan Transportation Science and Technology Project (Grant nos. 4-1, 2015) and the Sichuan Province Science and Technology Planning Project (Application Fundamental Research) (Grant no. 2020YFS0362).

\section{References}

[1] Z. H. Wang, L. C. Cai, Q. K. Gu, X. J. Liu, and A. H. Wu, "Modified calculation method of equivalent modulus of elasticity of foundation," Journal of Air Force Engineering University (Natural Science Edition), vol. 10, no. 6, pp. 23-27, 2009.

[2] X. S. Mao and X. L Zhi, "Checking method of construction deflection of semi-rigid base," Journal of Xi'an Highway University (Natural Science Edition ), vol. 23, no. 2, pp. 37-40, 2003.

[3] X. Liu, S. Song, Y. Tan et al., "Similar simulation study on the deformation and failure of surrounding rock of a large section chamber group under dynamic loading," International Journal of Mining Science and Technology, vol. 31, no. 3, pp. 495-505, 2021.

[4] Y. J. Jiang, J. L. Dai, and Z. D Chen, "Calculation method of equivalent modulus of elasticity of foundation under principles of different equivalence," Journal of Chang'an University (Natural Science Edition), vol. 25, no. 3, pp. 1-6, 2005.
[5] Y. Zhou, D. Zhao, B. Li, H. Wang, and Q. Zhang, "Fatigue damage mechanism and deformation behaviour of granite under ultrahigh-frequency cyclic loading conditions," Rock Mechanics and Rock Engineering, vol. 54, no. 9, pp. 47234739, 2021.

[6] X. Liu, D. Fan, Y. Tan et al., "New detecting method on the connecting fractured zone above the coal face and a case study," Rock Mechanics and Rock Engineering, vol. 54, no. 8, pp. 4379-4391, 2021.

[7] H. P. Wang, "Research on the revised coefficient of the recommended value for earth subgrade rebount modulus in the design of rigid pavement," China Journal of Highway and Transport, vol. 11, no. 4, pp. 1-20, 1998.

[8] Z. M. Tan and L. Wang, "Equivalent resilient modulus of subgrade based on principle of flexural-tensile stress equivalence," Journal of Highway and Transportation Research and Development, vol. 32, no. 3, pp. 46-50, 2015.

[9] Y. J. Jiang, C. L. Hou, X. F. Qin, and Z. D. Chen, "Calculation method of composite resilient modulus of foundation under cement concrete pavement," Journal of Highway and Transportation Research and Development, vol. 22, no. 5, pp. 38-42, 2005.

[10] Y. J. Jiang and J. L Dai, "Calculation method of equivalent modulus of elasticity of foundation under principles of thermal stress equivalence," Journal of Highway and Transportation Research and Development, vol. 23, no. 7, pp. 10-13, 2006.

[11] Y. Sun, G. Li, N. Zhang, Q. Chang, and J. Zhang, "Development of ensemble learning models to evaluate the strength of coal-grout materials," International Journal of Mining Science and Technology, vol. 31, no. 2, pp. 153-162, 2021.

[12] A. F. Jiang and Z. K. Yao, "Calculation of surface equivalent modulus of subgrade in the pavement structure," Journal of Tongji University: Natural Science Edition, vol. 29, no. 5, pp. 536-540, 2001.

[13] Z. M. Tan, Z. K. Yao, and B. Y. Liu, "Approximate calculation of equivalent modulus of end face of layered structures," Highways, vol. 48, no. 8, pp. 5-8, 2003.

[14] J. Vakili, "A simplified method for evaluation of pavement layers moduli using surface deflection data," Proceedings of the 12th International Conference of International Association for Computer Methods and Advances in Geomechanics (IAC$M A G)$, vol. 16, pp. 4314-4319, 2008.

[15] Q. K. Gu, R. Y. Zhang, B. Qu, and Y. Li, "Method on the calculation of compressive modulus based on loading test," Journal of Chang'an University (Natural Science Edition): Natural Science Edition, vol. 35, no. 1, pp. 56-60, 2015.

[16] J. M. Wu, R. Y. Du, and X. F. Wang, "Design method of asphalt pavement's overlay based on valid modulus," Journal of Chang'an University (Natural Science Edition), vol. 32, no. 4, pp. 1-6, 2012.

[17] S. Shao, C. Wu, M. Hao et al., "A novel coating technology for fast sealing of air leakage in underground coal mines," International Journal of Mining Science and Technology, vol. 31, no. 2, pp. 313-320, 2021.

[18] Y. Zhang, Y. Xie, Y. Zhang, J. Qiu, and S. Wu, "The adoption of deep neural network (DNN) to the prediction of soil liquefaction based on shear wave velocity," Bulletin of Engineering Geology and the Environment, vol. 80, no. 6, pp. 5053-5060, 2021.

[19] H. Rafezi and F. Hassani, "Drilling signals analysis for tricone bit condition monitoring," International Journal of Mining Science and Technology, vol. 31, no. 2, pp. 187-195, 2021. 
[20] X. S. Liu, D. Y. Fan, Y. L. Tan et al., "Failure evolution and instability mechanism of surrounding rock for close-distance parallel chambers with super-large section in deep coal mines," International Journal of Geomechanics, vol. 21, no. 5, 2021.

[21] L. Guo, Y. Zhou, and Z. Tan, "Loading stress of asphalt overlay on rubblized cement concrete pavement and related resilient modulus," Journal of Highway and Transportation Research and Development, vol. 5, no. 1, pp. 7-12, 2012.

[22] Z. M. Tan and X. H. Yu, "Calculation of sectional flexural stiffness equivalent modulus of asphalt pavement," China Journal of Highway and Transport, vol. 25, no. 6, pp. 37-42, 2012.

[23] Y. L. Xu, B. M. Tang, G. D. Xie, and S. Chen, "Back calculated modulus correction coefficient for asphalt concrete layer based on fwd," Journal of Chang'an University (Natural SciEnce Edition), vol. 32, no. 3, pp. 24-29, 2012.

[24] M. Cao, W. Huang, Y. Zou, and Y. Liu, "Modulus inversion layer by layer of different asphalt pavement structures," Advances in Civil Engineering, vol. 2021, pp. 1-10, Article ID 1928383, 2021.

[25] Z. M. Tan, "Simplified calculation of bi-layer plate bending with semi-continue condition," Highways, vol. 4, pp. 25-26, 2001.

[26] P. Li, "Study of the pavement modulus backnalysis using the database of FWD" Qingdao: Master's degree thesis of Shandong University of Science and Technology, 2007.

[27] C. Xiao, Y. J. Qiu, J. Zeng, and B. X. Li, "Measured dynamic response of asphalt pavement under fwd load," Journal of Highway and Transportation Research and Development, vol. 8, no. 4, pp. 1-9, 2012. 